\title{
Investigando a criatividade junto a professores: pesquisas brasileiras
}

\author{
Tatiana de Cássia Nakano
}

\begin{abstract}
Resumo
Considerando-se a criatividade como uma característica capaz de desenvolver o potencial do indivíduo e partindo-se da percepção da importância do estímulo à criatividade no ambiente escolar e do reconhecimento do papel do professor neste processo, este trabalho teve como objetivo identificar pesquisas brasileiras sobre criatividade realizadas com amostra de professores a fim de verificar o que tem sido estudado e os resultados que vêm sendo obtidos, visando traçar um quadro do que já se conhece acerca do fenômeno da criatividade junto a estes profissionais. Uma busca na base de dados Scielo foi realizada a partir da palavra chave criatividade, sendo que os 34 resultados foram considerados. Aqueles que apontaram ao longo do texto ou tendo como amostra a figura do professor foram analisados. Após seleção das pesquisas, as mesmas foram divididas de acordo com seu objetivo, de forma que foram agrupadas em relação à temática: influência da organização escolar sobre a criatividade, contribuição dos professores neste processo, concepção dos professores sobre a criatividade, capacidade dos mesmos identificarem a criatividade em seus alunos, dificuldades e limitações na criação de ambiente criativo, treinamento de modelos de atuação criativa. O que se verificou é que a influência exercida pelo professor no processo de desenvolvimento da criatividade na escola tem sido foco de atenção da maioria das pesquisas brasileiras. A análise das pesquisas aponta para um professor mal preparado, com grandes dificuldades para lidar com as diferenças individuais presentes nos alunos, desconhecedor de estratégias criativas e estimuladoras para ensinar e, ele próprio, desmotivado frente às condições institucionais que encontra em seu trabalho.
\end{abstract}

Palavras-chave: criatividade, professor, ambiente escolar.

\section{Investigating teachers creativity: brazilian research projects}

\begin{abstract}
Considering that creativity is a characteristic capable of developing the potential of the individual and considering the importance of the stimulation to the creativity in the school environment and the role of the teacher in the process,, this research verifies what has been studied in this field study in Brazil.. The study aimed at tracing a picture of what one already knows concerning the phenomenon creativity ..A Search in the database Scielo was carried using the word creativity. We considered 34 results got from our research, and we analyzed the terms related to the role of the teacher. After selecting the terms to be analyzed, we divided the definitions according to the theme and objectives:. the influence of the school organization on the creativity, contribution of the teachers in this process, conception of the teachers about creativity, teachers' ability to identify the creativity in their students, difficulties and limitations in the creative environment creation, training of models of creative performance. We verified that the influence of teacher on the process of creativity development in the school has been the focus of most of the Brazilian research. The analysis of the research points with respect to the figure of a teacher badly prepared, with great difficulties to deal with this issue. Individual differences students creativity and gifts do not receive attention from the teachers because they themselves do not feel motivated to tach due to the bad conditions of schools.
\end{abstract}

Key-words: creativity, teacher, school enviroment.

\section{Investigando la creatividad con profesores: estudios brasileños}

\begin{abstract}
Resumen
Considerando la creatividad como una característica capaz de desarrollar el potencial del individuo y a partir de la percepción de la importancia del estímulo a la creatividad en el ambiente escolar y del reconocimiento del papel del profesor en este proceso, este trabajo tuvo el objetivo de identificar investigaciones brasileñas sobre creatividad realizadas con muestras de profesores, con el fin de verificar lo que se ha estudiado y los resultados que están siendo alcanzados, buscando trazar un panorama de lo que ya se conoce acerca del fenómeno de la creatividad junto a estos profesionales. Una búsqueda en la base de datos Scielo fue realizada a partir de la palabra clave creatividad, siendo que los 34 resultados fueron considerados. Aquellos que señalaron a lo largo del texto o usando como muestra a la figura del profesor fueron analizados. Después de la selección de las investigaciones, las mismas fueron divididas de acuerdo con sus objetivos, de manera que fueron agrupadas en relación a la temática: la influencia de la organización escolar sobre la creatividad, contribución de los profesores en este proceso, concepción de los profesores sobre la creatividad, capacidad de los mismos de identificar la creatividad en sus alumnos, dificultades y limitaciones para formar un ambiente creativo, capacitación de modelos de actuación creativa. Lo que se verificó es que la influencia ejercida por el profesor en el proceso de desarrollo de la creatividad en la escuela ha sido punto de atención de la mayoría de las investigaciones brasileñas. El análisis de las investigaciones llama la atención para profesores mal preparados, con grandes dificultades para tratar las diferencias individuales presentes en los alumnos, sin conocimiento de estrategias creativas y estimuladoras para enseñar y, él mismo, desmotivado delante de las condiciones institucionales que encuentra su trabajo.
\end{abstract}

Palabras-clave: Creatividad, profesor, ambiente escolar.

Revista Semestral da Associação Brasileira de Psicologia Escolar e Educacional (ABRAPEE) * Volume 13, Número 1, Janeiro/Junho de 2009 * 45-53. 


\section{Introdução}

\section{A criatividade no contexto escolar}

O estudo da criatividade tem despertado um interesse crescente por parte de psicólogos e educadores que vêm desenvolvendo pesquisas a respeito das diferentes facetas compreendidas neste construto, tais como o processo, o produto, as pessoas e as condições ambientais que favorecem a expressão e o favorecimento da criatividade no ambiente escolar. Apesar do reconhecimento de que o ambiente educacional tem um papel importante no desenvolvimento da expressão criativa dos alunos, de acordo com Fleith e Alencar (2005), poucas tentativas têm sido feitas para se avaliar a extensão em que a criatividade tem sido estimulada ou inibida neste contexto.

$\mathrm{Na}$ área do desenvolvimento da criatividade, o ponto em que mais se tem centrado a atenção e que tem gerado o maior número de trabalhos de pesquisa e práticas de intervenção é constituído, segundo Martinez (1997), pelo papel da escola e pela percepção que os professores possuem acerca desta característica. Tal dado foi confirmado por pesquisa sobre o estado da arte em criatividade realizada por Wechsler e Nakano (2002, 2003), que envolveu a análise de trabalhos de 1984 a 2002 e indicou que, neste período, as pesquisas com amostras compostas por professores eram de $40 \%$ nas publicações periódicas e de $33,3 \%$ nas teses e dissertações.

Considerando a criatividade como um fenômeno multidimensional, que sofre influência de diversos aspectos, cognitivos, afetivos, ambientais e sociais (Wechsler, 1998), o que se sabe hoje é que existe um consenso entre os pesquisadores de que a criatividade deveria ser estimulada e desenvolvida no processo educacional, sendo que, no entanto, o sistema de ensino atual não estimula nem valoriza a formação de pessoas criativas. O chamado ensino tradicional, em que o estudante tem um papel fundamentalmente passivo, acaba por impedir o desenvolvimento da criatividade nos alunos. Notada como um fenômeno internacional, a preocupação provinda desta percepção, segundo Fleith e Alencar (1992) tem mostrado que pesquisadores de diversos países vêm apontando para a necessidade de se promover condições favoráveis à expressão criadora a fim de que o potencial criativo, presente em cada indivíduo, possa se desenvolver de forma mais adequada. Por esta e outras razões torna-se cada vez mais importante o papel que os professores exercem nesse processo, atentando para a importância de que se familiarizem com as características do pensamento criativo, conhecendo a maneira pela qual as capacidades criativas se desenvolvem, de forma que possam identificar os comportamentos e estimular os alunos em direção às suas possibilidades máximas.

Desta forma, reconhece-se a importância que o ambiente exerce sobre a criatividade, de forma que, segundo Amabile (1983), deve-se estudar esse construto sem perder de vista a sociedade na qual o indivíduo está inserido, uma vez que este ambiente pode influenciar de diversas maneiras, seja atuando como estimulador, recompensador, repressor ou punidor. A mesma opinião é compartilhada por Cropley (1999) ao afirmar que "ambientes cheios de normas e pressão ao conformismo atuam como inibitórios à criatividade na medida em que estimulam certos comportamentos e bloqueiam outros" (p.636). O autor complementa ainda que estudos apontaram que jovens criativos não estiveram sozinhos enquanto crianças. Eles tiveram contatos com pessoas mais experientes e receberam suporte destes, o que permitiu não somente um desenvolvimento mais flexível, mas também a eliminação dos bloqueios à sua criatividade.

Verifica-se internacionalmente que o avanço das pesquisas na área da criatividade faz com que o foco se altere a partir da década de 1970, com o surgimento da investigação do papel do contexto sociocultural no desenvolvimento da criatividade. O foco passou das habilidades cognitivas e traços de personalidade para a relação entre fatores sociais, culturais e históricos e o desenvolvimento da expressão criativa (Fleith \& Alencar, 2006), entretanto essa mudança de percepção demora a ser difundida no Brasil, fazendo com que os primeiros estudos da criatividade no ambiente educacional comecem a surgir por volta da década de 90 .

Neste sentido, a escola tem papel fundamental no desenvolvimento das crianças e jovens, uma vez que é neste meio que o aluno poderá explorar, elaborar e testar hipóteses e fazer uso de seu pensamento criativo. No entanto tais oportunidades serão possíveis se o professor estiver consciente de sua importância neste processo, de forma que esteja preparado para oferecer e permitir condições que possibilitem o desenvolvimento da criatividade na sala de aula, evitando o modelo perpetuado na maioria das escolas de ênfase à memorização, ao conformismo e à passividade.

Isto porque a educação formal apresenta como prioridade o desenvolvimento do pensamento lógico e a necessidade de se estar correto o tempo todo. Os alunos são sempre estimulados a buscarem a resposta "certa", como se existisse somente uma que respondesse ao problema. Mesmo reconhecendo que o processo de ensinoaprendizagem é bilateral (professor e estudante), o que acontece na prática é que tudo acaba ficando centralizado nas mãos do professor. É ele quem organiza o processo de ensino-aprendizagem, os objetivos que o aluno terá que alcançar e avalia os resultados obtidos. Nesta metodologia o estudante torna-se passivo em todo o processo, o que tende a frear o desenvolvimento da sua criatividade. Esta percepção é exposta por Martinez (1994) ao afirmar que a verdadeira criatividade é favorecida na escola por um clima permanente de liberdade mental, uma atmosfera que estimula, promove e valoriza o pensamento divergente e autônomo, a discrepância, a oposição lógica, a crítica fundada. Entretanto, "como podemos constatar, tudo isso é algo muito alardeado da boca para fora, mas rigorosamente punido em todos os níveis de nossas estruturas educativas" (Martinez, 1994, p.73). 
Por esta razão, a escola estaria pouco preparada para desenvolver o pensamento criativo dos alunos, uma vez que esse tipo de habilidade envolve características indesejáveis, tais como divergir do que é comum e tradicional, arriscar, experimentar novas idéias e utilizar também a intuição. No entanto, sabemos que a responsabilidade por este quadro atual tem início no processo de formação dos professores, que tende a prepará-los para lidar com o "aluno padrão", o "aluno obediente" e o "aluno passivo". Dessa maneira podemos compreender as dificuldades do professor ao se deparar com alunos bastante criativos ou ao se conscientizar das próprias barreiras que impedem a expressão da criatividade em seu trabalho.

Atentos à importância da figura do professor muitos estudos têm sido conduzidos com o objetivo de desenvolver as habilidades criativas dos indivíduos e de instrumentar estes profissionais para que estes se tornem mais efetivos no estabelecimento de condições favoráveis à criatividade na sala de aula. Segundo o levantamento realizado por Fleith e Alencar (1992), a grande maioria destes estudos foi realizada nos Estados Unidos onde ocorreu uma verdadeira revolução nos objetivos e métodos da educação em direção a um espaço maior para o amplo desenvolvimento da criatividade do aluno. Por outro lado, ainda de acordo com as autoras, em alguns países como o Brasil, tal preocupação começou a surgir apenas há uma década, com poucos estudos realizados sobre esta questão.

Ao se trabalhar com o tema da criatividade no ambiente escolar, não devemos nos esquecer que continuar insistindo no papel do professor como elemento único para estimular o crescimento, a expansão e a expressão das habilidades do aluno e para a construção de um auto-conceito positivo é insuficiente, de acordo com opinião de Joly (2001). Para a autora, além disso, são necessárias também mais pesquisas sobre criatividade e ambientes educacionais voltadas para a análise e a intervenção na rede de ensino brasileira, viabilizando as contribuições da ciência para a melhora das práticas educativas vigentes. De nada adianta "importar" práticas que obtiveram sucesso em outros países e que em nada correspondem à nossa realidade. Esta constatação reforça a importância de se avaliar o que tem sido pesquisado e trabalhado em nosso país em relação à criatividade no ambiente escolar, de forma que a análise destas pesquisas nacionais poderá nos fornecer importantes dados acerca do caminho que vem sendo traçado e dos esforços que ainda precisam ser feitos no sentido de melhorar o clima para o aprendizado, facilitando o trabalho do professor e tornando o aprendizado mais prazeroso para o aluno.

Assim, partindo da percepção da importância do estímulo à criatividade no ambiente escolar e do reconhecimento do papel do professor neste processo, este trabalho teve como objetivo verificar o que tem sido estudado no país e os resultados obtidos por pesquisas brasileiras realizadas com amostra de professores, visando traçar um quadro do que já se conhece acerca do fenômeno da criatividade junto a estes profissionais.
Neste sentido uma busca na base de dados Scielo (www.scielo.br) foi realizada a partir da palavra chave "criatividade". Dos resultados que retornaram, 34 ao total, todos aqueles que faziam menção ao professor, como participante de pesquisa ou em alguma referência ao longo do texto, foram analisados. Visando a uma organização, as pesquisas puderam ser agrupadas de acordo com a similaridade de seus objetivos.

\section{Pesquisas brasileiras sobre a criatividade no ambiente escolar}

Pesquisas que buscaram investigar a escola de uma forma geral serão enfocadas em primeiro lugar. A primeira pesquisa a ser citada, de Matos e Fleith (2006) buscou estudar o efeito do tipo de escola na criatividade dos alunos e no clima criativo. Para isso investigaram três tipos de escola: aberta, intermediária ou tradicional, em um total de 174 alunos. Os resultados apontaram, em relação à criatividade, um desempenho significativamente superior da escola aberta em relação à intermediária em apenas uma medida de criatividade (fluência), não tendo sido notada diferença em mais nenhuma característica. Já em relação à percepção do clima de sala de aula, os resultados indiciaram não haver diferenças significativas entre alunos de escola aberta, intermediária e tradicional. Assim, as autoras concluíram que não podemos apontar o melhor modelo de escola para o desenvolvimento do potencial criativo dos alunos. O que deve ser considerado são as características e necessidades do aluno, bem como o perfil desejado em cada tipo de escola, sendo necessário haver uma sintonia entre o perfil do aluno e o tipo de escola em que ele estuda a fim de se obter o máximo de aproveitamento escolar, permitindo assim, o desenvolvimento de todas as suas habilidades.

Nakano e Wechsler (2006b) estudando a organização escolar em outro ângulo, não considerando o tipo de modelo seguido e sim a diferença entre escolas públicas e particulares, também verificaram que esta influencia diretamente na criatividade dos alunos. Em sua pesquisa, realizada com 1426 estudantes do Ensino Fundamental, a variável tipo de escola (pública ou particular) exerceu influência significativa no desempenho criativo dos alunos, mostrando que alunos de escola particular, de uma forma geral, expressam melhor a sua criatividade, o que pode ser explicado pelo maior acesso a recursos e materiais.

Pesquisa de Fleith e Alencar (2008) que também avaliou esta variável junto a 239 alunos de $4^{\text {a }}$ série do ensino fundamental de quatro escolas do Distrito Federal, sendo duas públicas e duas particulares obteve resultados similares que sugeriram diferenças significativas entre alunos de escolas públicas e particulares em relação à criatividade $(F[1,225]=59,08 ; p=0,0001 ;$ eta2 $=0,21)$. Os alunos de escolas particulares apresentaram escore superior na medida de criatividade quando comparados aos de escolas públicas. Outra pesquisa das autoras também destacou que alunos das escolas particulares apontaram uma percepção mais positiva sobre a presença de clima criativo na sala de aula que os de escolas públicas (Fleith \& Alencar, 2006). 
Saindo do foco da organização escolar e voltando a atenção para um dos agentes mais importantes no desenvolvimento da criatividade na escola, as pesquisas a seguir buscaram investigar a contribuição de professores neste processo. Alencar (1998) com a finalidade de examinar a relação entre as habilidades de pensamento criativo de professores e alunos trabalhou com vinte e quatro professores e seus alunos. Todos responderam a um teste de criatividade, sendo que os resultados apontaram correlações significativas entre os resultados obtidos pelos professores e os resultados obtidos por seus alunos em uma das características da criatividade: a originalidade, sugerindo a influência destes profissionais nas habilidades criativas de seus alunos. Professores também foram avaliados por Alencar e Fleith (2004) durante o processo de construção de um instrumento que permite avaliar a percepção de estudantes universitários quanto à extensão em que seus professores favorecem o desenvolvimento e expressão da criatividade do aluno. Quatro fatores foram apontados pela análise fatorial e diziam respeito a: atributos do professor, dinâmica da sua prática docente, interesse pelo aluno e interesse por sua aprendizagem, demonstrando que através destas características o professor pode estar influenciando, por meio das suas práticas docentes, a criatividade de seus alunos.

Ainda comparando opiniões de alunos e professores do Ensino Médio, Silva (2000) buscou relacionar as características criativas destes profissionais e o tipo de aula ministrada, por meio de uma escala de comportamentos respondida tanto pelos professores como pelos alunos. Os resultados demonstraram uma discrepância entre as percepções. Enquanto os professores se auto descreviam como dinâmicos e motivadores, seus alunos percebiamnos como monótonos, havendo consenso somente em relação ao uso do humor, presente nas duas avaliações. Tais dados apontaram a existência de uma distorção entre o que o professor pensa idealmente sobre si mesmo e como ele é realmente percebido. Diferença esta que pode estar contribuindo para que a postura do professor continue sendo mantida, visto que para ele, encontra-se adequada, quando na realidade não está.

Além do envolvimento do professor e a avaliação que ele faz de sua atuação, a postura dos alunos é de fundamental importância para a aprendizagem. Um estudo de caso desenvolvido por Amaral e Martinez (2006) buscou identificar a relação entre o sentido da aprendizagem e a expressão da criatividade no processo de aprendizagem. As observações demonstraram a existência de vários elementos subjetivos que podem estar atuando no sentido de favorecer a criatividade do aluno, tais como um alto grau de motivação para a aprendizagem, capacidade de elaborar a informação recebida de forma individualizada, independência e autonomia para resistir a convenções e busca por novas experiências. A presença destes elementos, característicos nas pessoas criativas, acaba favorecendo a criação de um sentido para a aprendizagem, tornando-a prazerosa. Por este motivo, segundo as autoras, deveriam ser estimulados pelos professores como forma de tornar possível a expressão criativa do aluno, mas também se reforçando o papel ativo do mesmo nesse processo. Desta forma, o aluno criativo não se limita a reproduzir, mas se propõe a criar, a partir dos seus processos de aprendizagem, algo novo e valoroso para o seu processo de desenvolvimento. Com esta pesquisa vemos que embora o professor tenha um papel importante no processo de ensino-aprendizagem é de fundamental importância também o papel do aluno. Seu envolvimento poderá ser garantido a partir do momento em que uma atmosfera positiva estiver presente na sala de aula, e isso se torna possível nos espaços em que há a liberdade para expressão da criatividade e da individualidade.

Tais pesquisas confirmam a literatura, demonstrando que as atitudes dos professores influenciam de forma direta na criatividade dos alunos e que o conhecimento acerca desta característica e a tomada de consciência do papel que desempenham no desenvolvimento cognitivo, social e emocional dos alunos deveriam ser trabalhados junto aos professores durante sua própria formação, constantemente avaliados na sua prática profissional e incorporados ao processo de ensino-aprendizagem. Ao mesmo tempo tornase importante transferir o papel do professor como único propiciador da criatividade no processo de aprendizagem, dividindo essa responsabilidade com o aluno.

Mas para que isso se torne possível, primeiramente deve-se investigar a concepção que professores possuem acerca da criatividade na escola. Na fala de Ribeiro e Fleith (2007), fica claro que professores demonstraram possuir uma crença de que a criatividade depende somente de fatores intrapessoais e inatos, não sendo possível seu desenvolvimento, de forma que esse equívoco leva este profissional a desconsiderar a criatividade como uma dimensão importante em sala de aula, não procurando ferramentas de estímulo à criatividade neste contexto. Como forma de ilustrar esse quadro, alguns pesquisadores, tais como Martinez (1997), ao questionar 270 professores da Universidade de Havana acerca de quais eram os elementos que poderiam favorecer o desenvolvimento da criatividade de seus alunos encontrou resultados que indicaram com a maior porcentagem (mais de $50 \%$ das respostas) fatores como: método de ensino não tradicional, ensino produtivo e problematizado e garantia de independência do estudante. Contudo, o professor como modelo só foi assinalado por oito professores e a comunicação criativa professor-aluno, por dez (menos de 5\% da amostra pesquisada). De acordo com as constatações de Martinez (1997) isso revelou a necessidade de elaborar uma estratégia junto aos professores em que se enfatizasse adequadamente aquilo que é relativo ao desenvolvimento da criatividade, desfazendo os equívocos.

Tal dado mostra-nos que o professor não se vê, na maioria das vezes, como responsável pelo estímulo à criatividade na escola, quando deveria estar consciente do oposto. Consciente de que, segundo Alencar (1996), a escola, se deixar de se preocupar somente com a reprodução do conhecimento e passar a se preocupar também com a formação de alunos críticos e criativos, estará contribuindo para que estes possam enfrentar de uma forma 
mais criativa, problemas futuros. Preocupação esta que foi confirmada em pesquisa de Barreto e Martinez (2007) junto a quatro professores de pós-graduação stricto sensu ao confirmar a necessidade de trabalhar com os docentes para a implementação de uma prática pedagógica e orientação acadêmica baseadas nos pressupostos da criatividade e da inovação, através de um programa permanente de formação continuada. Os dados reforçam ainda a necessidade de investimento em processos educativos que primem pelo desenvolvimento da criatividade dos professores e em sua formação específica, por meio de estratégias e ações intencionais para o desenvolvimento da criatividade de seus estudantes.

Mourão e Martinez (2006) também procuraram investigar a relação entre o sentido da criatividade para o professor e a sua prática pedagógica. A partir do acompanhamento de dois professores de uma mesma escola, as autoras descobriram que embora a criatividade possa ser vista como um fenômeno interativo, isso nem sempre garante a aplicação desta característica por parte do professor. Ao ver o aluno como um elemento que também os avalia, os professores tenderiam a evitar o uso do espaço da sala de aula como recurso criativo, perpetuando o processo tradicional de ensino-aprendizagem visto que desta forma pouco ou nenhum espaço seria dado ao aluno para a elaboração de críticas e avaliações do trabalho que vem sendo desenvolvido. Por outro lado, após conseguir atravessar a resistência dos professores e ampliar o espaço de aprendizagem para outros locais além da sala de aula, alguns professores demonstraram grande satisfação ao conhecerem uma vivência diferenciada da qual não tinham conhecimento e perceberam que esta pode ser utilizada como recurso adicional para o ensino. Assim, vemos que um trabalho de conscientização acerca dos benefícios de trazer a criatividade para a sala de aula e a implementação de recursos diversificados precisam ser feitos com a finalidade de desfazer os mitos que ainda persistem entre os professores.

Atenta a esta realidade, Pereira (2001) focou sua pesquisa no interesse em saber se seria possível ajudar o professor a se tornar mais criativo, investigando por meio de uma escala quais seriam as ações a serem realizadas neste sentido junto a alunos do curso de Pedagogia. Segundo estes, as áreas mais necessitadas de aprofundamento para sua formação como professor foram a criatividade na educação, seguida pela pesquisa e posteriormente a atitude questionadora. $\mathrm{Na}$ opinião da pesquisadora, estas três áreas poderiam ser englobadas dentro de um mesmo tema nos cursos de Pedagogia, considerando-se que a pesquisa e o questionamento formam partes integrantes de um mesmo conteúdo que é o ensino criativo e suas aplicações no currículo acadêmico. Neste mesmo sentido, Oliveira (1997) investigou a percepção do processo de ensinoaprendizagem e as expectativas e valores dos professores que estão iniciando a carreira da Pedagogia. Assim, a pesquisadora solicitou a alunos e professores que listassem, por meio de adjetivos, as características mais importantes de um professor ideal e as existentes no professor real. Os três adjetivos mais frequentemente utilizados para o professor ideal, em ordem decrescente, foram "criativo", "atualizado" e "amigo". Já para a descrição do professor real apareceram "cansado", "desvalorizado" e "mal remunerado". Tais dados refletem, de uma maneira bastante clara, o idealismo com que o professor inicia a sua carreira e como descrevem, de maneira oposta, os seus colegas de profissão.

Neste mesmo sentido de identificar e comparar as características do professor real e ideal, Oliveira e Wechsler (2002) descobriram junto a 90 estudantes universitários que as três características que mais descreviam o professor real, segundo eles eram "cansado", "desvalorizado" e agressivo". Já em relação ao professor ideal, seriam "criativo", "amigo", "pesquisador" e "atualizado". Interessante pesquisa foi relatada por Sousa (2001) ao aplicar um questionário em uma amostra de 852 estudantes e 245 professores evidenciando que os alunos se imaginavam, caso fossem professores, como mais criativos do que os professores vêem a si próprios. Para estes profissionais a criatividade e a eficácia são consideradas qualidades excludentes, sendo que esta tendência não foi verificada entre os alunos ao se imaginarem como professores.

As pesquisas demonstram a necessidade de revisão da formação de professores, os quais não têm sido preparados para lidar com a realidade educacional brasileira. Perante as dificuldades encontradas na prática profissional, reforça-se a importância do uso da criatividade como recurso auxiliar na resolução dos problemas encontrados no dia a dia da escola. Para Ribeiro e Fleith (2007), a escassez de informação sobre criatividade e as lacunas na formação do professor explicam o desconhecimento dos professores acerca das ferramentas direcionadas à expressão criativa, fazendo com que os professores acabem por utilizar de forma quase intuitiva os poucos conhecimentos que possuem.

Segundo Mariani e Alencar (2005), as dificuldades relatadas por estes profissionais incluem a falta de habilidade na relação com o aluno que os impede de se expressar criativamente, dificuldade em adequar sua linguagem à faixa etária do aluno de forma a tornar a comunicação mais eficiente, dificuldade no controle da disciplina e inabilidade em organizar aulas diversificadas, sem que isso comprometa o conteúdo. Pesquisa de Alencar e Fleith (2008b) junto a 398 professores do Ensino Fundamental indicou que as barreiras mais indicadas pelos professores à promoção da criatividade em sala de aula foram: elevado número de alunos em classe, alunos com dificuldades de aprendizagem e baixo reconhecimento do trabalho do professor (apontadas por $51,4 \%, 47,3 \%$ e $43,8 \%$ dos professores respectivamente). Três outras barreiras que tiveram expressiva indicação foram a extensão do programa a ser cumprido no decorrer do ano letivo, desinteresse do aluno pelo conteúdo ministrado e escassez de material didático disponível na escola (apontadas respectivamente por $38,2 \%, 38,5 \%$ e $38,5 \%$ dos docentes).

Estes dados nos mostram que embora haja um consenso por parte dos pesquisadores acerca da 
importância de se estimular e desenvolver a criatividade na escola, sendo essa uma das metas educacionais que deve receber atenção por parte dos governos de um modo geral os professores não estão preparados para lidar com esse tipo de ensino e nem oferecem as condições adequadas para a sua expressão. Isto porque estes profissionais ainda possuem idéias errôneas acerca dessa característica, tais como pensar que ela não pode ser desenvolvida, ensinada ou aprendida. Tal crença acaba fazendo com que os alunos desenvolvam poucas habilidades, devido também ao extenso programa da escola brasileira, aliado ao curto período de tempo que o aluno permanece na escola.

Neste processo, grande é a responsabilidade do professor, visto que para desenvolver e orientar a criatividade em seus alunos é necessário que este conheça as características comportamentais dos indivíduos criativos, os traços de personalidade e as condições internas e externas que favorecem ou impedem a sua realização e o desenvolvimento de suas aptidões, interesses, atitudes e motivações (Campos \& Weber, 1987). Buscando demonstrar essa realidade, outras pesquisas foram realizadas com o objetivo de investigar a capacidade de professores em identificar a criatividade na sala de aula. Alencar (1998) realizou em 1974 uma avaliação da extensão que professores do ensino fundamental seriam capazes de discriminar entre seus alunos mais criativos e aqueles menos criativos. Os professores responderam a um instrumento no qual deveriam apontar os alunos que mais apresentavam e os que menos apresentavam fluência, flexibilidade e originalidade em suas idéias (características descritoras de pessoas criativas). Ao mesmo tempo os alunos responderam a testes de pensamento criativo. Os resultados mostraram que os professores não conseguiam apontar corretamente os alunos mais e menos criativos, de forma a apresentar uma grande dificuldade em avaliar as habilidades criativas de seus alunos. Os docentes também demonstraram que conheciam pouco sobre tais habilidades visto que não utilizavam qualquer método para estimular esta característica em sala de aula. O mesmo objetivo foi alvo de pesquisa em outra amostra de professores (Alencar, Fleith, Nobre, \& Shimabukuro, 1986), sendo que os resultados se repetiram, apontando a inabilidade dos mesmos em avaliar a criatividade dos alunos, mesmo após terem recebido orientações acerca da criatividade e de como favorecer a sua expressão.

Os dados nos mostram que mesmo sem conhecer e apresentar capacidade de identificar a criatividade em seus alunos, pesquisas realizadas em diversos países e relatadas por Wechsler (1998) confirmam que professores de diferentes culturas preferem mais os estudantes obedientes, conformistas e sociáveis do que aqueles que são questionadores, independentes e intuitivos, ou seja, comportamentos que caracterizam o indivíduo criativo. Estes não são valorizados na sala de aula, sendo indesejados ou punidos. Neste mesmo sentido, Alencar e Rodrigues (1978) buscaram investigar as características mais valorizadas pelos professores em seus alunos, tendo participado da pesquisa 239 professores do Ensino Fundamental. Os dados indicaram que mais de $95 \%$ gostariam que seus alunos apresentassem características como: ser obediente, sincero, atencioso, trabalhador, popular e bem aceito pelos colegas. No oposto, características ligadas à criatividade não foram consideradas importantes, tais como independência de pensamento, curiosidade e autoconfiança.

O que pudemos ver com estas pesquisas é que embora fatores favoráveis ao desenvolvimento do potencial criativo sejam reconhecidos (no discurso) como importantes e necessários por parte dos professores, inúmeras limitações e dificuldades encontradas no ambiente escolar acabam impedindo a construção de um clima propício e favorável à criatividade. A começar pela dificuldade dos professores em identificar a criatividade na sala de aula por desconhecimento das suas características. O que acaba ocorrendo é que, segundo Alencar (1995), quem tem acesso às escolas pode observar que não é raro o professor distribuir os seus alunos em fileira de acordo com seu desempenho ou obrigar aqueles mais atrasados a se sentarem sempre no final da classe. Essa disposição tende a reforçar as expectativas do professor, que sabe, antecipadamente, quem produzirá ou não o esperado. Tal fato sugere que muitos dos professores estão desinformados a respeito do impacto que tais atitudes possuem sobre o aluno, ao rotulá-lo de forma indireta como incapaz ou separá-lo de seus companheiros em função de um desempenho acadêmico que deixa a desejar. Isto pode estar acontecendo com os alunos criativos. Tudo porque apresentam características que são vistas pelos professores como indesejáveis quando na verdade professores poderiam estar fazendo uso da criatividade para solucionar antigos problemas escolares, tais como o fracasso escolar, e para melhorar o desempenho dos alunos e as relações interpessoais, entre outros (Mariani \& Alencar, 2005).

Após tantos anos de pesquisas que cada vez mais reforçaram a importância em se estimular e valorizar a criatividade, alguns modelos de atuação criativa dos professores e programas de estimulação foram criados e testados. Muitas inovações educativas foram experimentadas e aplicadas com êxito para ativar o processo de aprendizagem e o papel ativo do aluno. Os princípios do ensino foram problematizados e jogos, simulações e dinâmicas de grupo passaram a ter cada dia maior aplicação na escola, "pois permitem um melhor processo de apropriação de conhecimentos e habilidades, bem como o incremento de capacidades cognitivas diversas, especialmente aquelas do tipo criativo" (Martinez, 1997, p.169). O uso destas técnicas também pode contribuir para mudanças nas atitudes dos alunos em relação ao processo de ensino e aprendizagem, favorecendo o envolvimento pessoal e o desenvolvimento de interesses e motivações fundamentais para a criatividade.

Tais dados puderam ser confirmados em pesquisa de Alencar, Fleith e Rodrigues (1990) que buscou avaliar vinte e dois professores de $3^{a}$ e $4^{a}$ séries que participaram de um programa de treinamento de criatividade tendo como objetivo familiarizar os participantes com as diversas técnicas existentes para o desenvolvimento do pensamento 
criativo. Outro grupo controle de 24 professores também foi avaliado. Após quinze encontros o que se pôde verificar é que os professores que participaram do treinamento obtiveram resultados mais altos nos testes de criatividade do que os professores do grupo controle, tanto no momento imediatamente posterior ao término dos trabalhos como numa segunda medida realizada cinco meses após seu término. Este treinamento criativo permitiu o desenvolvimento da consciência de que as técnicas para a solução criativa de problemas e a montagem de cursos e seminários para o desenvolvimento da criatividade devem e podem ser incorporados às matérias do currículo. Seu domínio por parte dos professores é uma importante premissa para que, de forma coerente e criativa, haja uma fusão entre esses elementos e as matérias.

Considerando que os professores são beneficiados com o treinamento em criatividade, Alencar e Fleith (2003) realizaram estudo buscando avaliar quais seriam as barreiras à expressão da criatividade pessoal a fim de que um programa adequado às necessidades fosse criado. Uma amostra de 544 professores de distintos níveis de ensino foi utilizada, sendo que os resultados apontaram que a falta de tempo/ oportunidade foi o fator mais frequentemente citado, referindo-se a condições externas ao indivíduo que dificultam o uso do seu potencial para criar: falta de reconhecimento, de oportunidade e de tempo. Foram apontados também fatores intrínsecos, tais como inibição, timidez e falta de motivação. Mariani e Alencar (2005) também encontraram junto a 16 professores do Ensino Fundamental que os principais elementos limitadores da expressão criativa na sua atividade docente foram a conduta de alguns alunos (falta de motivação, imaturidade, agressividade, brincadeiras em sala de aula), além da sobrecarga de trabalho, da falta de recursos materiais e de estrutura educacional (distanciamento entre o discurso e a prática). Cavaco (1995) em sua pesquisa também demonstrou que os fenômenos sociais influenciam a imagem que o professor tem de si próprio e de seu trabalho, e que a política educacional não colabora com a formação do professor ideal, criativo, pesquisador, atualizado e bem remunerado.

Estas pesquisas mostram-nos que embora não sejam abundantes os trabalhos que procuram explorar especificamente o papel da personalidade do professor no estabelecimento de um clima criativo na sala de aula, conforme apontado por Martinez (1997), é indiscutível que os recursos de personalidade que estes possuem influirão na sua ação como sujeito da relação interativa com os alunos, justificando a necessidade de treinamento e desenvolvimento da sua própria criatividade, incluindo a aquisição de um repertório de comportamentos adequados a serem praticados pelos professores, tais como o reforço do comportamento apresentado pelos alunos, a criação de um ambiente de resistência ao conformismo, o oferecimento de um refúgio seguro para os estudantes quando eles forem expostos a críticas feitas por outros alunos e professores e a garantia de uma atmosfera permissiva à criatividade em sala de aula.
Em outro oposto, após terem sido apresentadas as pesquisas nas quais os professores fizeram uma autoavaliação, apresentaremos a seguir, pesquisas nas quais os estudantes também foram indagados a avaliarem seus professores. Alencar (2002), por exemplo, traça um perfil do professor facilitador e inibidor da criatividade segundo opinião de 92 estudantes de pós-graduação e observou que o uso adequado ou não de técnicas instrucionais foram os aspectos mais citados pelos pós-graduandos para descrever tanto o perfil do professor facilitador quanto do professor inibidor das habilidades criativas dos alunos. Santeiro, Santeiro e Andrade (2004) repetindo o mesmo objetivo desta pesquisa, obtiveram junto a 117 estudantes universitários que o preparo do professor foi o fator preponderante $(36,06 \%)$ em se tratando da facilitação da criatividade dos alunos, sendo que as mesmas técnicas instrucionais citadas por Alencar (2002) obtiveram somente 15,17\%. Já a pesquisa de Teixeira e Alencar (2000) junto a alunos de graduação mostrou que o professor facilitador seria, segundo os alunos, aquele descrito como inteligente, que domina a disciplina que ensina, ensina de forma eficaz e gosta de dar aulas.

A observação destas pesquisas nos mostrou que, se por um lado houve divergência entre o modo como os alunos caracterizam o professor facilitador e inibidor da criatividade e formas como os próprios professores se avaliam, por outro, isso acabou por implicar em justificar a ausência da criatividade na sala de aula devido a comportamentos e atitudes dos alunos, e pelo despreparo do professor. A percepção de tal divergência somente reforça a necessidade e a relevância de se instrumentar o professor para o desenvolvimento das habilidades criativas de seus futuros alunos, paralelamente ao desenvolvimento de suas próprias habilidades criativas.

No contexto escolar, condições necessárias à expressão da criatividade podem ser implementadas ao se prover condições apropriadas de aprendizagem, de acordo com Fleith e Alencar (2008). Em relação ao professor, as autoras afirmam que o profissional que é comprometido com o desenvolvimento da criatividade de seus alunos é mais flexível, estabelece uma relação positiva com seus alunos, estimula o questionamento em sala de aula, valoriza produtos e ideias criativas, tem expectativas positivas em relação ao desempenho dos alunos, demonstra entusiasmo pela atividade docente e dá oportunidade de escolha ao aluno, considerando seus interesses e habilidades.

Para alcançar estes objetivos os professores apontados como criativos em diversos estudos apresentam comportamentos como: (1) encorajam os estudantes a aprenderem de forma autônoma e independente do professor, (2) estimulam um modelo de ensino cooperativo em que alunos e professores se sentem responsáveis, (3) motivam os estudantes a terem muitas ideias, estimulando o uso de atividades que permitam ao aluno pensar de forma divergente sobre os problemas, (4) promovem a autoavaliação dos estudantes e estabelecem junto a estes as metas a serem alcançadas, (5) estão abertos às sugestões dos alunos, (6) oferecem aos estudantes oportunidades de trabalharem 
com uma grande variedade de materiais e sob diferentes condições em ambientes que muitas vezes vão além da sala de aula, (7) desenvolvem um clima de tolerância na sala de aula através de abertura e espaço para elaboração de questões, respostas e sugestões inesperadas.

Assim, o professor desempenha um papel essencial no processo de ensino-aprendizagem, contribuindo para a promoção da produtividade criativa em sala de aula na medida em que, de acordo com Fleith (2007), domina o conteúdo que ensina, tem entusiasmo pelo conteúdo que leciona e pela atividade docente e faz uso de uma diversidade de técnicas instrucionais, acomodando diversos estilos de aprendizagem de seus alunos.

\section{Considerações Finais}

Partindo-se destes apontamentos da literatura e das pesquisas nacionais relatadas, pode-se notar que todos os pesquisadores salientaram a importância da conscientização dos professores e futuros professores do papel que exercem junto aos alunos, da necessidade de serem facilitadores da aprendizagem e estimuladores do potencial criativo, estabelecendo desta forma uma atmosfera em sala de aula mais propícia à produção e não apenas à reprodução do conhecimento.

No entanto, o indivíduo pode se tornar criativo em função de uma série de influências, sem que se torne possível determinar todas as possibilidades. O que se pode afirmar é que enfatizar a escola como um dos elementos que pode estar agindo tem sido a conclusão de muitos estudos e pesquisas que evidenciaram a sua condição de facilitadora da criatividade. Diante disto, este trabalho teve como objetivo enfatizar aqueles elementos que, amparados pela pesquisa e pela prática, evidenciaram-se como estimuladores da criatividade, reconhecendo a importância dos programas de estimulação.

Assim, pudemos perceber que a dificuldade na utilização do espaço escolar como local de desenvolvimento da criatividade reside no fato de que, segundo Martinez (2002), para se trabalhar a criatividade na escola, deve-se trabalhar no mínimo em três direções: no desenvolvimento da criatividade dos alunos, da criatividade dos educadores e da criatividade como organização. Alguns passos já foram dados, mas muito ainda falta até que se consiga trazer efetivamente a criatividade para o ambiente escolar.

Por fim, como pudemos ver, a importância do professor no desenvolvimento da criatividade de seus alunos é inquestionável. Cabe a ele desenvolver o processo docente de tal forma que contribua para estimular a criatividade. Pode ainda criar o clima criativo que deve existir na sala de aula para alcançar esse objetivo. Também o professor, utilizando as técnicas de que dispõe, pode ser habilitado a detectar as potencialidades criativas de seus alunos, ajudando-os a se expressarem. Resulta daí a importância da implantação de programas de identificação e esclarecimento em criatividade nas escolas brasileiras que sirvam de base para uma modificação dos padrões atuais de ensino e que permitam o desenvolvimento mais sadio e completo de nossos estudantes.

\section{Referências}

Alencar, E. M. L. S. (1998). Desenvolvendo o potencial criador: 25 anos de pesquisa. Cadernos de Psicologia, 4 (1), 113-122.

Alencar, E. M. L. S. (2002). O estímulo à criatividade em programas de pós-graduação segundo seus estudantes. Psicologia: Reflexão e Crítica, 15(1), 1-8.

Alencar, E. M. L. S., \& Fleith, D. S. (2003). Barreiras à criatividade pessoal entre professores de distintos níveis de ensino. Psicologia: Reflexão e Crítica, 16(1), 63-69.

Alencar, E. M. L. S., \& Fleith, D. S. (2004). Inventário de práticas docentes que favorecem a criatividade no ensino superior. Psicologia: Reflexão e Crítica, 17(1), 105-110.

Alencar, E. M. L. S., \& Fleith, D. S. (2008). Barreiras à promoção da criatividade no ensino fundamental. Psicologia: Teoria $e$ Pesquisa, 24(1), 59-65.

Alencar, E. M. L. S., Fleith, D. S., Nobre, M. P., \& Shimabukuro, L. (1986). Efeitos de um programa de treinamento de criatividade para professores em sua habilidade de identificar alunos mais e menos criativos. Anais da XVI Reunião Anual de Psicologia ( $\mathrm{p}$ 13). Ribeirão Preto: SBP.

Alencar, E. M. L. S., Fleith, D. S., \& Rodrigues, A. M. (1990). Avaliação a médio prazo de um programa de treinamento de criatividade para professores do ensino do primeiro grau. Estudos de Psicologia, 1(1), 79-97.

Alencar, E. M. L. S., \& Rodrigues, C. J. S. (1978). Relação entre tempo de ensino, localidade da escola e características comportamentais consideradas desejáveis e indesejáveis por professores do ensino do primeiro grau. Arquivos Brasileiros de Psicologia Aplicada, 30, (75-93).

Amabile, T. M. (1983). The social psychology of creativity. New York: Springer-Verlag.

Amaral, A. L. N., \& Martínez, A. M. (2006). Aprendizagem e criatividade no contexto universitário. Psicologia para América Latina, 8. Recuperado: 24 set. 2007. Disponível: http://pepsic. bvspsi.org.br/scielo.php?script=sci_arttext\&pid=\$1870350X200 6000400003\&lng=pt\&nrm=isso.

Barreto, M. O., \& Martínez, A. M. (2007). Possibilidades criativas de professores em cursos de pós-graduação stricto sensu. Estudos de psicologia (Campinas), 24(4), 463-473.

Campos, D. M. de S., \& Weber, M. G. Criatividade. Rio de Janeiro: Sprint.

Cavaco, M. H. (1995). Ofício do professor: o tempo e as mudanças. Porto: Porto.

Cropley, A. J. (1999). Education. Em M. A Runko \& S. R. Pritzker, Encyclopedia of Creativity (Vol.1, pp. 629-642). San Diego, CA: Academic Press.

Fleith, D. S. (2007). A promoção da criatividade no contexto escolar. Em A. M. R. Virgolim (Org.), Talento criativo: expressão em múltiplos contextos (pp. 143-158). Brasília: Editora Universidade de Brasília.

Fleith, D. S., \& Alencar, E. M. L. S. (1992). Efeitos de um programa de treinamento de criatividade em estudantes normalistas. Estudos de Psicologia, 9(2), 09-38.

Fleith, D. S., \& Alencar, E. M. L. S. (2005). Escala sobre o clima para criatividade em sala de aula. Psicologia Teoria e Pesquisa, 21(1), 85-91. 
Fleith, D. S., \& Alencar, E. M. L. S. (2006). Percepção de alunos do ensino fundamental quanto ao clima de sala de aula para criatividade. Psicologia em Estudo, 11, 513-521.

Fleith, D. S., \& Alencar, E. M. L. S. (2008). Características personológicas e fatores ambientais relacionados à criatividade do aluno do Ensino Fundamental. Avaliação psicológica, 7(1), 35-44.

Joly, M. C. R. A. (2001). A criatividade verbal e sua importância nos ambientes educacionais. Psicologia Escolar e Educacional, 5(2), $11-20$

Mariani, M. F. M., \& Alencar, E. M. L. S. (2005). Criatividade no trabalho docente segundo professores de História: limites e possibilidades. Psicologia Escolar e Educacional, 9(1), 27-35.

Martínez, A. M. (1994). Comportamiento humano: nuevos métodos de investigación. Madrid: Editorial Escuela Española.

Martínez, A. M. (1997). Criatividade, personalidade e educação (M. Pinto, Trad.). Campinas, SP: Papirus.

Martínez, A. M. (2002). Creatividad y salud en los indivíduos y en las organizaciones. Creatividad y Sociedad, 1(1), 25-32.

Matos, D. R., \& Fleith, D. S. (2006). Criatividade e clima criativo entre alunos de escolas abertas, intermediárias e tradicionais. Psicologia Escolar e Educacional, 10(1), 109-120.

Mourão, R. F., \& Martínez, A. M. (2006). A criatividade do professor: a relação entre o sentido subjetivo da criatividade e a pedagogia de projetos. Psicologia Escolar e Educacional, 10(2), 263-272.

Nakano, T. C., \& Wechsler, S. M. (2006). Teste Brasileiro de Criatividade Figural: proposta de normas. Avaliação Psicológica, 5(2), 159-170.

Oliveira, E. T. A. (1997). Variáveis que afetam a aprendizagem: percepção de alunos de licenciatura e professores. Dissertação de Mestrado, Pontifícia Universidade Católica de Campinas, Campinas, São Paulo.

Oliveira, E. T. A., \& Wechsler, S. M. (2002). Variáveis que afetam a aprendizagem: percepção de alunos de licenciatura e professores Psicologia Escolar e Educacional, 6(2), 133-139.

Pereira, M. (2001). Inteligência e criatividade: duas trajetórias alternativas para as crianças sobredotadas?. Psicologia: Teoria, investigação e prática, 6(1), 171- 188.

Ribeiro, R. A., \& Fleith, D. S. (2007). O estímulo à criatividade em cursos de licenciatura. Paidéia, 17(38), 403-416.

Santeiro, T. V., Santeiro, F. R. M., \& Andrade, I. R. (2004). Professor facilitador e inibidor da criatividade segundo universitários. Psicologia em Estudo, 9(1), 95-102.

Silva, P. A. (2000). Criatividade do professor no ensino médio. Dissertação de Mestrado, Pontifícia Universidade Católica de Campinas, Campinas, São Paulo.

Sousa, F. C. (2001). Criatividade e eficácia no ensino superior: percepções de Estudantes e professores. Psicologia: Teoria, investigação e prática, 6(1), 189-213.

Teixeira, J. N., \& Alencar, E. M. L. S. (2000). Atributos do professor universitário facilitador da criatividade. Anais da $X X X$ Reunião Anual de Psicologia (p. 176). Brasília: SBP.

Wechsler, S. M. (1998). Criatividade: descobrindo e encorajando. São Paulo: Editora Psy.

Wechsler, S. M., \& Nakano, T. C. (2002). Caminhos para a avaliação da criatividade: perspectiva brasileira. Em R. Primi (Org.), Temas em Avaliação Psicológica (pp. 103-115). São Paulo: Instituto Brasileiro de Avaliação Psicológica.

Wechsler, S. M., \& Nakano, T. C. (2003). Produção brasileira em criatividade: o estado da arte. Escritos sobre Educação, 2(2), 4350.

Recebido em: 27/11/2007

Reformulado em: 19/05/2009

Aprovado em: 17/07/2009

Sobre a Autora

Tatiana de Cássia Nakano

Pós-doutoranda Universidade São Francisco.

Bolsista FAPESP. 